\title{
Limites geográficos da pluma de odor da Estação de Tratamento de Esgotos de Curado, Recife-PE, Nordeste do Brasil
}

\section{Marcos Theófilo Silvério da Silva ${ }^{1}$, Ronaldo Faustino da Silva', João Manoel de Freitas Mota $^{2}$ e Renata Maria Caminha de Oliveira Carvalho ${ }^{2}$}

${ }^{1}$ Instituto Federal de Pernambuco. Curso de Mestrado Profissional em Gestão Ambiental. Campus Recife. Av. Prof. Luís Freire, 500. Cidade Universitária, Recife-PE, Brasil (CEP 50740-545).E-mail: mtheofilo@mail.org.

${ }^{2}$ Instituto Federal de Pernambuco. Diretoria de Pós-Graduação. Campus Recife. Av. Prof. Luís Freire, 500. Cidade Universitária. Recife-PE, Brasil (CEP 50740-545).

Resumo. Os incômodos proporcionados por maus odores, resultante de atividades antrópicas, é uma questão ambiental cada vez mais recorrente, devido ao desconforto ambiental em populações locais sob influência da pluma. A ausência de norma nacional de parametrização do método de apuração dos incômodos representa um desafio ambiental para o poder público e a gestão ambiental. A EN 16841-1:2016 e a EN 16841-2:2016, inspirada na norma alemã VDI 4302-1 e VDI 4302-2, aplicada na avaliação do odor no ambiente, compreende técnicas e métodos sensoriais de inspeções de campo para a determinação da extensão da pluma de odores reconhecíveis, mediante painel humano qualificado é o padrão orientado aos países membros pelo Comitê Europeu de Padronização para qualidade do ar. Neste método, o aparelho olfativo humano é usado como tecnologia de êxito não replicável artificialmente na identificação real in loco de reconhecimento dos compostos odorantes, a partir de uma fonte sabida. Isto posto, o objetivo principal deste trabalho é mensurar os limites geográficos de flutuação da pluma odorante no território de influência da estação de tratamento de esgotos, a ETE Curado, situado em Recife-PE. A pesquisa rege-se pela proposta do método europeu da pluma dinâmica VDI 4302-2, mais simples de aplicar e menos oneroso, na perspectiva do não uso de meios não-humanos de captura do efeito adverso do odor. 0 procedimento de seleção e qualificação do painel humano de avaliadores se norteou nos métodos ASTM 679 e ASTM 544, tomando como substância de referência a acetona. A investigação situacional da região de movimentação da penumbra odorante procedeu no período de seis meses, de fevereiro a julho do ano de 2019. Com os resultados obtidos foi possível estabelecer os marcos territoriais de flutuação da pluma, constituindo-se em
Recebido

$20 / 02 / 2021$

Aceito

$25 / 04 / 2021$

Publicado

$30 / 04 / 2021$

Acesso aberto

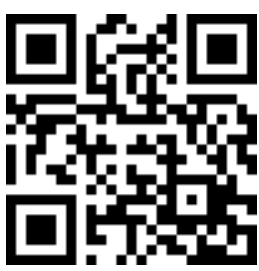

ORCID

(D) 0000-0003-4790-0631

Marcos Theófilo

Silvério da Silva

(D) 0000-0001-8097-9420

Ronaldo Faustino da

Silva

(D) 0000-0001-7961-5494 João Manoel de Freitas Mota 
subsídios relevantes para planejamento das atividades da ETE e subsidiariamente a propositura de um guia prático de aplicação do método da pluma dinâmica VDI 4302-2.

Palavras-chave: Emissões gasosas; Poluição atmosférica; Gestão ambiental; Ventos.

\section{Abstract. Geographic limits of the odor plume of the Sewage} Treatment Station of Curado, Recife-PE, Northeast Brazil. The discomfort caused by bad odors, resulting from human activities, is an increasingly recurrent environmental issue, due to environmental discomfort in local populations under the influence of the plume. The absence of a national norm for parameterizing the method for calculating nuisances represents an environmental challenge for public authorities and environmental management. EN 16841-1:2016 and EN 168412:2016, inspired by the German standard VDI 4302-1 and VDI 4302-2, applied in the evaluation of odor in the environment, comprises techniques and sensory methods of field inspections to determine the extension of the plume of recognizable odors, through a qualified human panel is the standard given to member countries by the European Standardization Committee for air quality. In this method, the human olfactory apparatus is used as a successful technology that is not artificially replicable in the real on-site identification of odorant compounds, from a known source. That said, the main objective of this work is to measure the geographic limits of fluctuation of the odorous plume in the territory of influence of the sewage treatment plant, the ETE Curado, located in Recife-PE. The research is governed by the proposal of the European method of dynamic plume VDI 4302-2, simpler to apply and less costly, in the perspective of not using non-human means of capturing the adverse effect of odor. The selection and qualification procedure of the human panel of evaluators was based on the ASTM 679 and ASTM 544 methods, using acetone as the reference substance. The situational investigation of the region of movement of the odorous penumbra proceeded in the period of six months, from February to July of the year of 2019. With the obtained results it was possible to establish the territorial fluctuation landmarks, constituting relevant subsidies for planning activities of the ETE and, alternatively, the proposition of a practical guide for the application of the VDI 4302-2 dynamic plume method.

Keywords: Gaseous emissions; Atmospheric pollution; Environmental management; Winds.
0000-0002-9993-8212

Renata Maria Caminha de Oliveira Carvalho

\section{Introdução}

A questão dos odores tem-se evidenciado na sociedade como causa de incômodos e representa um impacto ambiental decorrente da constância e concentração de compostos 
odorantes indesejáveis, notadamente no vetor fonte de emissões e da comunidade sob influência da penumbra odorante (Silva, 2020).

Neste cenário, novos desafios ambientais emergem, de forma colateral e paralelo aos já contabilizados malefícios a qualidade ambiental decorrentes do modelo produtivo de fluxo de energia desfavorável a natureza e do tratamento ambiental e não-ambiental de resíduos sólidos e semissólidos, através da problemática ambiental e dos incômodos a qualidade de vida dos humanos resultantes da emissão atmosférica de odores (Silva, 2020).

O impacto dos odores nas áreas circundantes a uma fonte depende de diferentes fatores, como a quantidade de odores emitidos no local, a distância da fonte, as condições climáticas, topografia, além da sensibilidade a odores e tolerância da vizinhança (Silva, 2020).

O contato sensorial prolongado em concentrações medianas pode causar reações adversas no ser humano, como distúrbios do sono, ansiedade, mal-estar, dor de cabeça e até depressão; e de sintomas físicos, incluindo náuseas, irritações sensoriais e problemas respiratórios (McGinley et al., 2000).

Os odores correspondem a maior parcela de reclamações relacionadas à poluição atmosférica no mundo (Mcginley et al., 2000). 0). Portanto é imperativo estudos e pesquisas para avaliar esse tipo de impacto, assim como também buscar soluções para equacionar essa questão (Mcginley et al., 2000). No Brasil tem crescido a geração de resíduos sólidos urbanos (ABRELPE, 2019). A economia que se move pelo crescimento da produção industrial, associado ao aumento do consumo, resulta em mais resíduos e a ausência de tratamento ambientalmente adequada, acarreta efeitos adversos ao meio ambiente (ABRELPE, 2019).

A concentração dos danos advindos de destinos inadequados é evidente nas áreas periféricas das cidades, visualmente perceptíveis e agravados pela ausência de disposição e tratamento adequados, inevitavelmente, atingem à saúde das pessoas, a paisagem e a qualidade ambiental dos ecossistemas e da biodiversidade (ABRELPE, 2019).

Adensa a essa questão, o incremento da geração de gases do efeito estufa (GEE), $\left(\mathrm{CH}_{4}, \mathrm{~N}_{2} \mathrm{O}\right.$ e $\left.\mathrm{CO}_{2}\right)$, e de odores, mais evidentes nos destinos inadequados, conquanto presentes também nos equipamentos de tratamento ambientalmente adequados, como aterro sanitário, central de compostagem e estação de tratamento de esgotos (Belli Filho et al., 2007).

Ao contrário de algumas emissões que se caracterizam pela identificação e quantificação de compostos específicos, as emissões de odores representam uma complexidade no tocante a quantificar e estabelecer níveis de concentrações, já que o impacto do odor é raramente resultado de um único composto, mas sim uma combinação de centenas de diferentes compostos odoríferos (Vieira, 2013).

O lançamento atmosférico de odores tem o campo de influência determinado pelas correntes de ar, com ampliação do raio de atuação variável pela atividade cinética dos ventos, afetando a qualidade de vida de comunidades impactadas pela atuação de fontes de odor, decorrente, sobretudo, da ação antropogênica de geração do efluente gasoso incomodante (Brand, 2014).

A avaliação do impacto e dispersão de odores advindos de empreendimentos com real potencial de emissão do efluente odorífico sob uma região afetada, é um desafio enfrentado por diversos países no mundo (Mendes, 2012).

$\mathrm{Na}$ perspectiva de formas diversas de compreensão da aplicação de métodos de identificação e monitoramento do efluente gasoso, resultante de um conjunto preponderante de compostos químicos voláteis de uma fonte reconhecida, emerge a importância da constituição do arcabouço legal para a instrumentalização do estado na fixação de parâmetros de regulação de atividades emanadoras de odores incomodantes (Vieira, 2013). 
O aborrecimento olfativo é considerado um indicador de um ambiente insalubre pela população e o ponto de partida são as queixas, não sistemáticas, variadamente distribuídas e tecnicamente frágeis, à princípio, não nos permite concluir o incômodo percebido, mas apresenta-se como indicativo de investigação (Silva, 2020).

0 procedimento de caracterização detalhada das substâncias que integram odor, envolve o uso de métodos analíticos, de técnicas e aparelhos para a identificação e quantificação, tais como cromatografia gasosa e a espectrometria de massa (métodos indiretos) (Mendes, 2012).

A aplicação de método baseado em espectrometria de massa tem como finalidade, os estudos e a aplicação na avaliação e compreensão esmiuçada de compostos odorantes existentes no ambiente em estudo (Mendes, 2012).

A olfatometria de diluição dinâmica é um método que utiliza painelistas especializados para medir a frequência do odor e dá uma indicação da concentração (Mendes, 2012). Nesta perspectiva, os painelistas utilizam um dispositivo respiratório (olftômetro) que dilui o ar ambiente exterior odorífero com ar fresco (sem odor), trata-se de um método híbrido, semi-humano (Mendes, 2012). 0 nariz eletrônico é o método definido como um sistema composto da união de detectores (sensores químicos) que interpreta os sinais sob a forma de impressões digitais, assentada nos pressupostos da inteligência artificial, que intenta a reprodução por meio não-humano de uma percepção humana, porém incerto na precisão de odores em campo, devido à incapacidade de detecção em baixas concentrações (Capanema et al., 2016).

Noutro sentido, há as técnicas sensoriais de inspeção de campo, denominadas de método da grade e da pluma, respectivamente representadas pelas normas alemãs VDI 4302-1 e VDI 4302-2, reconhecida pela praticidade de aplicação, que em 2016 foi submetida a apreciação por câmaras temáticas específicas de avaliação e, consecutivamente, foi convertida pelo Comitê Europeu para Padronização nas Normas Europeias EN 16841:1 e EN 16841:2, indicada para adesão dos países membros da comunidade europeia (CEN, 2016a, 2016b).

A inspeção de campo é baseada em um painel de examinadores qualificados (métodos diretos) sem auxílio de equipamento e, apresenta-se como opção metodológica de mensuração territorial de expansão da pluma e da avaliação do impacto de incômodos por odores que aproxima o fenômeno da realidade perceptiva humana (em oposição as técnicas instrumentais e químicas) (Brattoli, et al., 2016). 0 painel humano, constituído por membros devidamente selecionados e treinados, estão aptos a identificar os odores em campo e tipo de sensação que proporciona (nível de agradabilidade do odor percebido) e reproduzi de forma mais próxima e genuína a percepção olfativa dos residentes circunvizinhos à fonte dos odores incomodantes, favorecendo a caracterização do território impactado (Carmo Junior, 2005; Sironi et al., 2005).

No contexto brasileiro, a reação e reclamação da população exposta aos maus odores, encontram entraves pela ausência de lastro legal que situe a gravidade do fato perante a instância ambiental do poder executivo, devido à falta de tipificação exata do objeto e que delega voluntariamente ao setor privado o compromisso da gestão ambiental no desafio de incrementar custos verdes aos processos de mitigação da externalidade por maus odores, decorrente do tratamento de resíduos orgânicos sólidos e semissólidos em parâmetros não sabidos (Silva, 2020).

O vácuo legal [a Lei dos Crimes Ambientais, Lei no 9.605/1998, prever multa para quem provoca poluição de qualquer natureza, sendo necessário um relatório de constatação] frustra a tentativa de interessados de recorrer a instâncias administrativas ou judiciais na resolução da questão, bem como na fixação de limites de emissão odorantes desagradáveis em plantas industriais, equipamentos de tratamento de resíduos orgânicos sólidos e semissólidos e de estação de tratamento de esgoto e efluentes líquidos (Schirmer et al., 2008). 
Regulamentações internacionais sobre emissões de odor e a influência num espaço territorial, tendem a considerar o emprego de avaliadores humanos como um método valioso e menos oneroso para mensurar o impacto do odor por inspeção em campo (Brattoli, et al., 2016). Destacadamente, o método alemão VDI 4302-2 que foi adotado em 2016 pelo comitê europeu de normalização, sob a nomenclatura de EN 16841, que em suma, trata-se de um método de inspeção de campo procedido por avaliadores qualificados, a fim de obter índices quantitativos de incômodo e mensuração da pluma de odor (CEN, 2016).

O presente artigo propõe a metodologia alemã VDI 4302-2 para registro dos limites geográficos de flutuação da pluma de odor no território sob influência das emissões de uma estação de tratamento de esgotos (ETE), com o intuito de contribuir e subsidiar a gestão ambiental do empreendimento.

\section{Metodologia}

O presente estudo incidiu sobre a Estação de Tratamento de Esgoto de Curado (ETE Curado), localizada no município de Recife-PE, no Bairro de Curado, com a geolocalização de latitude $S 8^{\circ} 03^{\prime} 39,41^{\prime \prime}$ e longitude $034^{\circ}$ 59' 5,86", próximo ao terminal interestadual de passageiros - TIP (Figura 1).

0 método de investigação dos incômodos provocados pelos odores utilizou a modelação da pluma dinâmica (VDI 4302-2), na perspectiva de dimensionamento espacial de flutuação da pluma, contemplando as áreas habitadas e de circulação de pessoas no entorno do equipamento. A determinação do comprimento e largura da pluma foi restringida, em termos de precisão, devido às características topográficas da região em estudo. A pesquisa aconteceu nos meses de fevereiro a julho de 2019, contou com a presença de oito painelistas selecionados e qualificados. Para a determinação e arquitetura da pluma foram realizadas marcações em 2220 pontos de registros de presença e ausência da percepção odorífica. As características locais de tempo, orografia e rugosidade nortearam a flutuação da pluma, em períodos distintos do dia, determinada pela direção e força dos ventos.

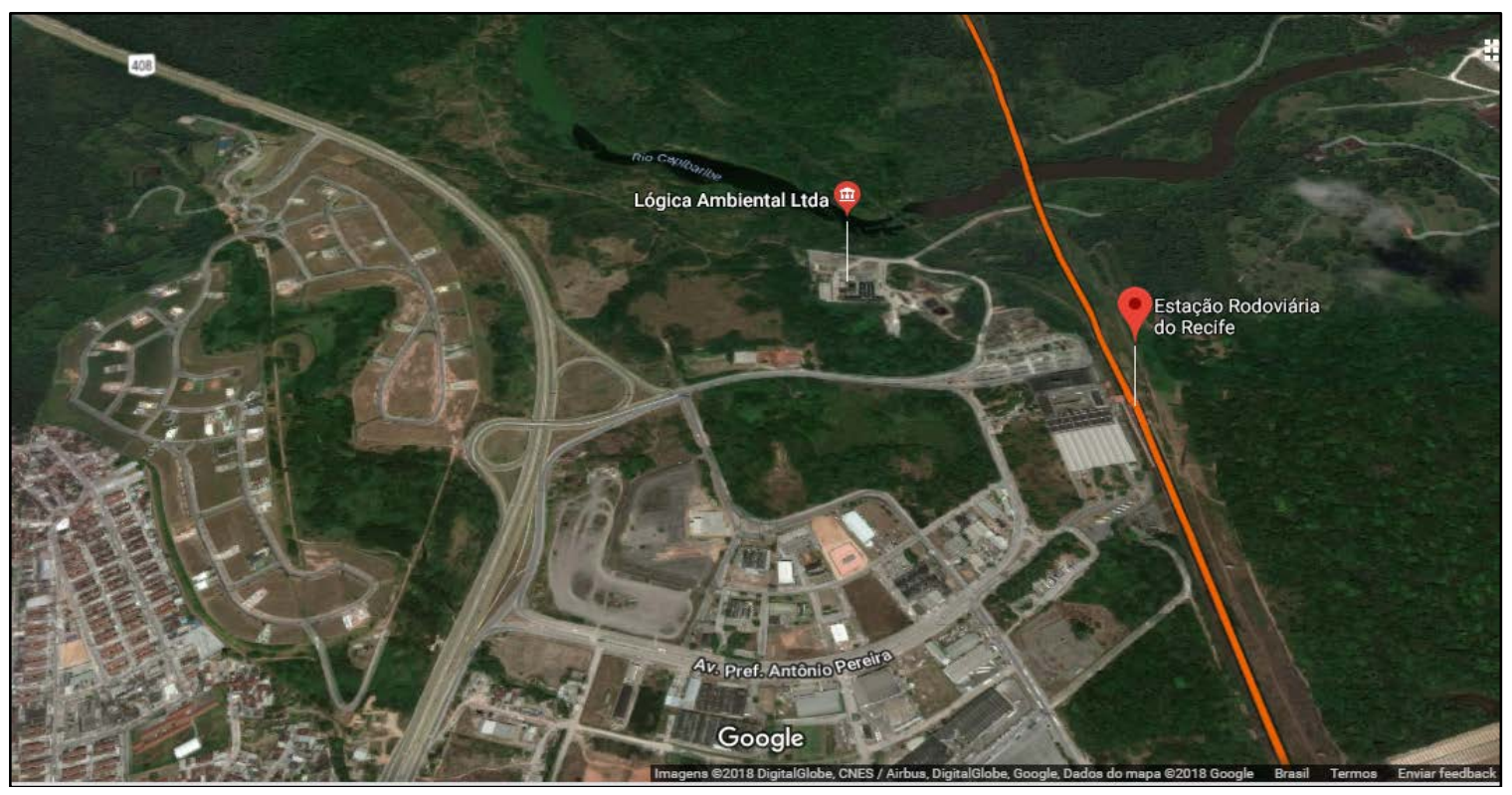

Figura 1. Visão aérea da ETE Curado. Fonte: Google Maps (2020) 
Os procedimentos de medição foram procedidos seguindo o regulamento Europeu, a norma alemã, VDI 4302-2, ou seja, o Método da Pluma Odorante (Figura 2), que determina a extensão detectável e reconhecível dos odores de uma fonte específica, mediante inspeção de campo por painel humano selecionado e qualificado. A técnica de avaliação prevê o uso de formulário de medição para apontamento das detecções no formato binário sim/não, constituindo as marcações georreferenciadas da região sob influência detectável de odores da fonte estudada e, a modelagem mensurada da expansão máxima da pluma. A topografia do local, a existência e o distanciamento de áreas verdes, as comunidades circunvizinhas e as condições climáticas locais; foram fatores considerados no estudo.

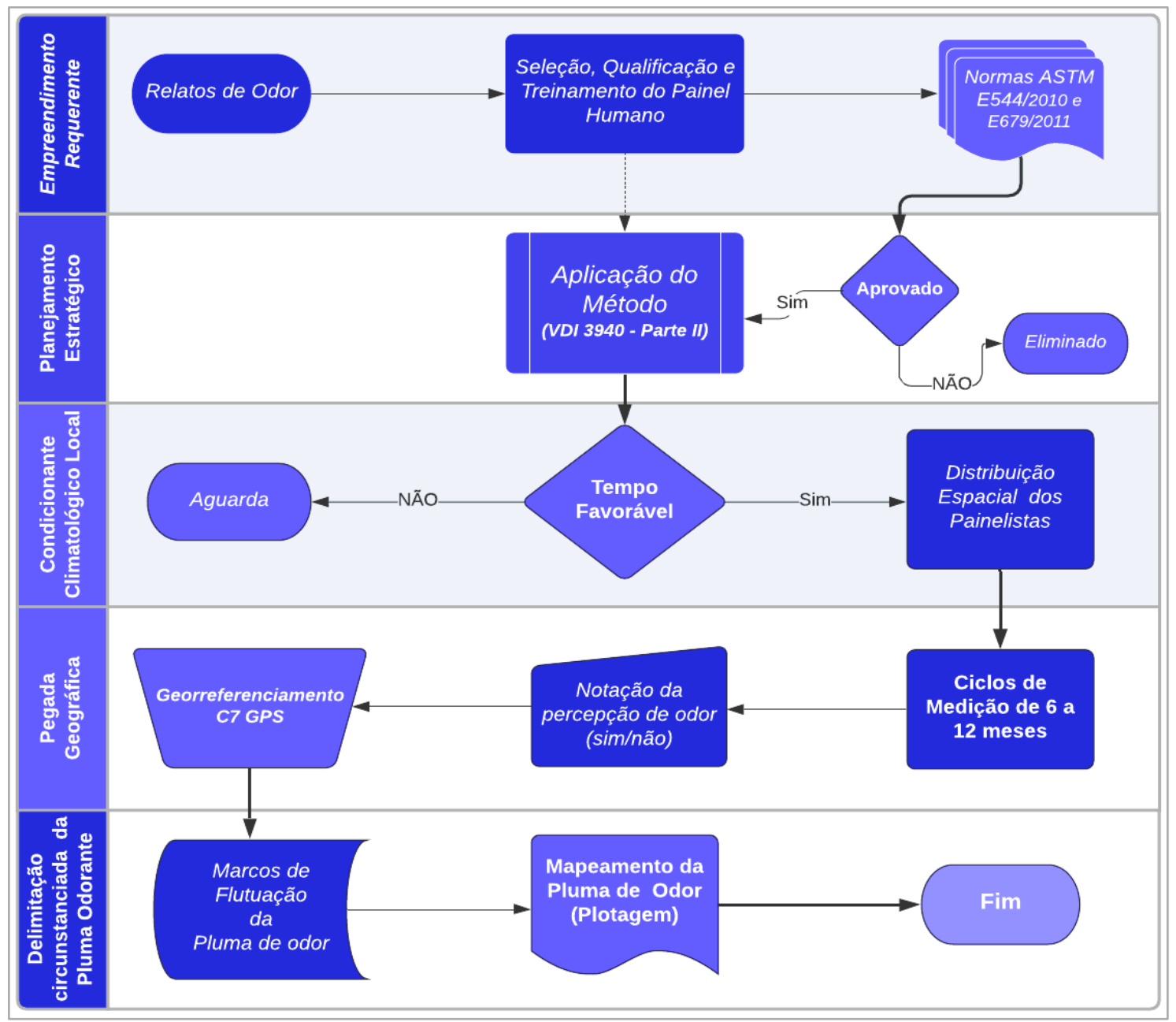

Figura 2. Fluxograma de aplicação da metodologia VDI 4302-2

As normas americanas, ASTM E544/2010 e E679/2011 foram usados como métodos de referência para qualificação dos jurados (painelistas). A norma ASTM prevê como substância de referência o n-butanol, no entanto, não exclui a possibilidade de uso de outra substância odorífica. Para o presente estudo, entre as amostras de controle em branco, utilizou-se como substância de referência a propanona $\mathrm{CH}_{3}(\mathrm{CO}) \mathrm{CH}_{3}$ ) (ISO, 2012; Fachbereich Umweltmesstechnik, 2015). 0 objetivo do teste é a escolha de candidatos que 
representem uma percepção olfativa mediana da população, no intento de identificar e excluir os postulantes extremamente sensíveis ou insensíveis ao odor de referência (acetona), sem a pretensão de selecionar e formar painelistas especializados. 0 processo de qualificação foi realizado no Laboratório da Empresa Lógica Ambiental, sob supervisão do responsável técnico pelo laboratório. O espaço destinado ao teste sensorial foi configurado tomando como referência a ABNT ISO 8589:2015 (ABNT, 2015). Os parâmetros aplicados na substância de referência foram adaptados para o uso da acetona (Tabela 1).

Tabela 1. Comparativo da acetona com o n-Butanol.

\begin{tabular}{|l|c|c|}
\hline \multicolumn{1}{|c|}{ Parâmetro } & Acetona & n-Butanol \\
\hline PM & 58,08 & 74,12 \\
\hline Densidade de vapor & $(\mathrm{ar}=1): 2,0 \mathrm{a} 20^{\circ} \mathrm{C}$ & $2,55(\mathrm{ar}=1) \mathrm{a} 20^{\circ} \mathrm{C}$ \\
\hline Densidade & 0,790 & 0,810 \\
\hline Taxa e evaporação & $<1$ (acetato de butila $=1)$ & $0,46$ (acetato de butila $=1)$ \\
\hline Odor & Próprio & Próprio \\
\hline
\end{tabular}

Cálculos da metodologia referenciada na norma ASTM adaptada a acetona:

$$
\begin{aligned}
\text { i. } & \mathrm{Cb}=2,5 \mathrm{ppmv}=2,5 \mathrm{ml} / 10^{6} \mathrm{ml} \\
\text { ii. } & \mathrm{Vb}=200 \times\left(2,5 / 10^{6}\right)=0,0005 \mathrm{ml}=0,5 \mathrm{ul} \\
\text { iii. } & \mathrm{Vt}=200,0005 \mathrm{ml} \sim 200 \mathrm{ml} \\
\text { iv. } & \mathrm{Mb}=0,0005 \times 0,790=3,95 \times 10^{-4} \mathrm{~g} \\
\text { v. } & \mathrm{Nb}=3,95 \times 10^{-4} / 58,08=6,800 \times 10^{-6} \text { moles } \\
\text { vi. } & \mathrm{Kh} \text { à } 25^{\circ} \mathrm{C}=1,870 \times 10^{-5} \mathrm{~atm} \cdot \mathrm{m}^{3} \cdot \mathrm{mol}^{-1} \\
\text { vii. } & \mathrm{Pb}=1,870 \times 10^{-5} \times 0,0340=6,36 \times 10^{-7} \mathrm{~atm}
\end{aligned}
$$

A dosagens utilizadas de acetona em $200 \mathrm{~mL}$ de água destilada estão informadas na Tabela 2.

Tabela 2. Volumes de acetona utilizados no teste.

\begin{tabular}{|c|c|c|}
\hline Frasco & Volume & Observações \\
\hline 1 & $8 \mu \mathrm{L}$ & - \\
\hline 2 & $16 \mu \mathrm{L}$ & - \\
\hline 3 & $32 \mu \mathrm{L}$ & - \\
\hline 4 & $64 \mu \mathrm{L}$ & Limite de percepção odorante para acetona \\
\hline 5 & $128 \mu \mathrm{L}$ & - \\
\hline 6 & $256 \mu \mathrm{L}$ & - \\
\hline
\end{tabular}

A qualificação dos candidatos tomou como parâmetro a junção das normas ASTM E679/2011 (ASTM Internacional, 2011) e E544/2010 (ASTM Internacional, 2010). A apresentação do teste deu-se com seis fileiras de três Erlenmeyers de $500 \mathrm{~mL}$. Cada uma das fileiras continha 2 Erlenmeyers com $200 \mathrm{~mL}$ de água destilada (inodora) e um Erlenmeyer contendo uma solução de acetona com água destilada, contendo $200 \mathrm{~mL}$. Os Erlenmeyers contendo acetona são conhecidos apenas pelo operador do teste de seleção. As concentrações seguiram uma ordem crescente. 0 candidato ao adentrar na sala de teste recebeu um formulário para apontamento de suas apostas. No processo de avaliação dos candidatos no teste de qualificação, a aprovação se deu com os seguintes condicionantes: 


\section{Condição 1:}

A aposta assertiva do candidato do recipiente com a concentração de $64 \mu \mathrm{L}$ da escala de diluição da acetona em água, equivalente ao LPO, conforme adaptação da norma americana ASTM E544/2010.

\section{Condição 2:}

A maior eficiência de aprovação acontecerá se os aprovados no teste qualificação tiverem seu Limite de Percepção Individual for identificado com preponderância de acertos entre as concentrações $32 \mu \mathrm{L}$ e $128 \mu \mathrm{L}$, da escala, segundo a adaptação da norma americana ASTM E544/2010.

\section{Condição 3:}

O candidato será reprovado se o resultado da avaliação individual resultante do cálculo do logaritmo de base 10 estiver fora dos limites definido pelo desvio padrão (calculado pela média do conjunto dos resultados do logaritmo de base 10 do grupo de avaliadores), conforme a adaptação da norma americana ASTM E679/2011.

A convocação de candidatos resultou no interesse de dezessete pessoas, sendo nove do sexo feminino e oito do sexo masculino, com idade entre 20 e 59 anos; o quantitativo real de doze participantes no teste, com três desistências pós-teste e uma reprovação, totalizando oito painelistas efetivamente qualificados. 0 resultado final da seleção, conforme os critérios advindos de adaptações das normas ASTM E679-04/2011 (ASTM Internacional, 2011), ASTM E544-18/2010 (ASTM Internacional, 2010) e dos condicionantes, foram 11 candidatos qualificados para composição do painel humano de avaliadores de odores em campo e um reprovado, conforme a aplicação dos cálculos constante na norma ASTM E679-04 presentes na Tabela 3 devido ao não atendimento das condicionantes 1 e 3.

Tabela 3. Julgamentos sensoriais de doze candidatos de amostras de acetona diluída em água destilada.

\begin{tabular}{|c|c|c|c|c|c|c|c|c|c|}
\hline \multirow[b]{2}{*}{ Candidato } & \multicolumn{6}{|c|}{ Julgamento das seis concentrações de acetona $(\mu \mathrm{L})$} & \multicolumn{3}{|c|}{ Resultados - LPO dos candidatos } \\
\hline & 8 & 16 & 32 & 64 & 128 & 256 & Valor (MG) & $\begin{array}{c}\log ^{10} \mathrm{do} \\
\text { valor }\end{array}$ & Situação \\
\hline 1 & + & + & 0 & + & + & + & 45,25 & 1,66 & aprovado \\
\hline 2 & 0 & + & 0 & + & + & + & 45,25 & 1,66 & aprovado \\
\hline 3 & + & 0 & + & + & + & + & 22,63 & 1,35 & aprovado \\
\hline 4 & 0 & + & 0 & + & + & + & 45,25 & 1,66 & aprovado \\
\hline 5 & + & 0 & + & + & + & + & 22,63 & 1,35 & aprovado \\
\hline 6 & 0 & + & 0 & + & + & + & 45,25 & 1,66 & aprovado \\
\hline 7 & + & 0 & 0 & + & + & + & 45,25 & 1,66 & aprovado \\
\hline 8 & 0 & 0 & 0 & + & + & + & 45,25 & 1,66 & aprovado \\
\hline 9 & + & 0 & 0 & + & + & + & 45,25 & 1,66 & aprovado \\
\hline 10 & + & 0 & + & + & + & + & 22,63 & 1,35 & aprovado \\
\hline 11 & + & 0 & + & + & + & + & 22,63 & 1,35 & aprovado \\
\hline 12 & + & + & + & 0 & 0 & + & 181,02 & 2,26 & reprovado \\
\hline \multirow{4}{*}{\multicolumn{7}{|c|}{ Média Geométrica (MG) das Apostas dos Candidatos (GAC) }} & $\sum \log 10$ & 19,27 & \\
\hline & & & & & & & $\begin{array}{c}\text { Média } \\
\left(\sum \log 10 / 12\right) \\
\end{array}$ & 1,61 & \\
\hline & & & & & & & Média (GAC) & 78,28 & \\
\hline & & & & & & & DP $(\log 10)$ & 0,25 & \\
\hline
\end{tabular}

Fonte: Yang (2017). 
A coleta de dados meteorológicos foi obtida em equipamento próximo ao local de estudo, situado no bairro da Várzea, na estação meteorológica do Recife (A301) (INMET, 2020). Foram utilizados dados da variável vento (velocidade e direção) apresentados no formato de rosa dos ventos, no período de fevereiro a julho de 2019 , obtidos no banco de dados (metadados) e do software de acesso online gratuito pertencente a instituição de ensino, Iowa State University - College of Agriculture and Life Sciences (IASTATE, 2019) e, os dados sobre as condições do clima e do tempo, através da Agência Pernambucana de Águas e Clima (APAC). A análise procedida mediante o registro de dados de direção predominante no formato de porcentagem (\%). 0 registro de dados no período considerou a velocidade média, mensuradas por metros por segundo $\left(\mathrm{m} / \mathrm{s}^{-1}\right)$.

As medições da pluma de odores, orientada pela norma europeia, a metodologia alemã VDI 4302-2, situou-se na região de influência da fonte. Contemplou o período de seis meses, de fevereiro a julho de 2019. Os eixos de medição não foram lineares, uma vez que as condições locais, não permitiram a localização dos assessores em todas as localidades, devido à dificuldade de acesso em áreas vegetadas e de corpos d'água, no entanto, uma vez que todos os pontos de medição foram devidamente referenciados, este fato não se obstaculizou o trabalho desenvolvido (Figura 3).

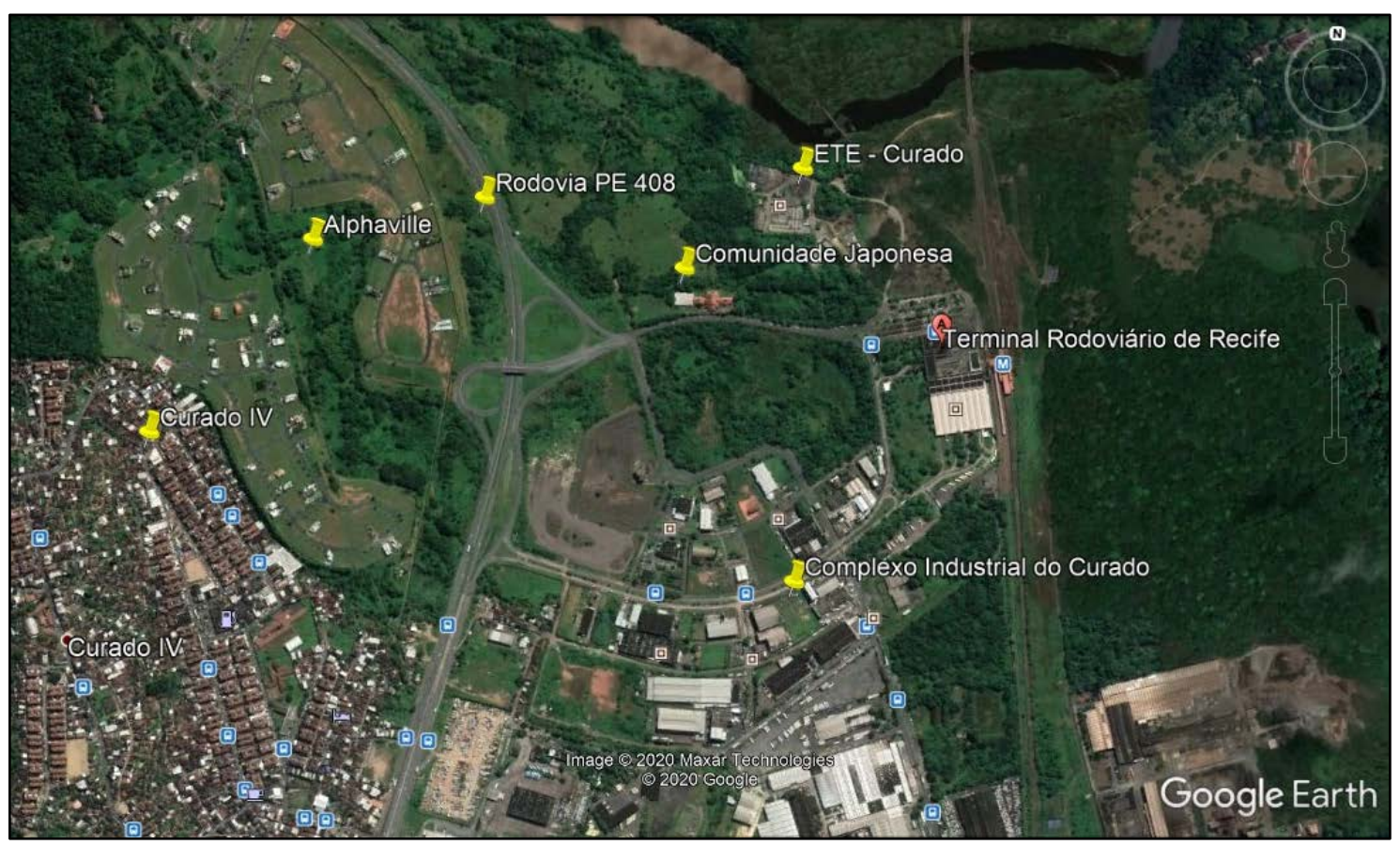

Figura 3. Área de pesquisa. Fonte: Google Earth (2020).

\section{Resultados}

0 perfil de temperatura na microrregião apresentou uma variação de $24^{\circ} \mathrm{C}$ a $29^{\circ} \mathrm{C}$, com baixas temperaturas no período noturno e temperatura média durante o dia de $26^{\circ} \mathrm{C}$. A velocidade média apurada no período correspondeu a 4,9 m/s (Figura 4). A força dos ventos predominante no período foi de grau 3, segundo a escala Beaufort de classificação de intensidade dos ventos, descrita como vento fraco, ou seja, a transferência de energia cinética apenas capaz de produzi a movimentação das folhas das árvores. A velocidade mensal mínima registrada no período foi observada em abril com 4,1 m/s e a velocidade 
máxima em junho com 5,6 m/s. A predominância da direção dos ventos no período foi de sul-sudeste (Figura 4). Durante os meses de junho a setembro, o fluxo de radiação solar é intensificado e consequentemente aquece a superfície terrestre, fornecendo energia cinética, com isso o ar quente mais leve do que o ar frio tem a tendência a subir, criando ciclos mais intensos de movimentação de parcelas de ar. Os ventos oscilaram com velocidades entre $5,3 \mathrm{~m} / \mathrm{s}$ e $5,9 \mathrm{~m} / \mathrm{s}$ e velocidade média de $5,6 \mathrm{~m} / \mathrm{s}$, sendo mais intenso do que a média de $4,9 \mathrm{~m} / \mathrm{s}$, apurada durante os doze meses do ano (superior em 16\%). No entanto, a maior velocidade dos ventos no descolamento de parcelas de ar, no lapso temporal avaliado, não altera a força dos ventos, mantendo-se na escala de grau 3 de Beaufort, por estar situada no intervalo de velocidades entre $4,0 \mathrm{~m} / \mathrm{s}$ e $6,0 \mathrm{~m} / \mathrm{s}$. As características do vetor vento durante as inspeções de campo orbitaram no segundo quadrante da rosa dos ventos, marcada por três direções: sul-sudeste, sudeste e léssudeste, com a predominância no período de estudo da direção sul-sudeste (SSE) (Figura 4). Os ventos em fluxos baixos, conforme a escala Beaufort de número 3, proporcionaram que as inspeções de campo ocorressem com múltiplos períodos de ventos fracos e consequentemente com baixa mobilidade da pluma de odor. A falta de odor observável (não percebido) em condições favoráveis de tempo e direção de vento ocorreram devido à inexistência de uma dinâmica suficiente para geração do efluente gasoso na ETE capaz de ser percebido no raio de influência nas avaliações em campo.

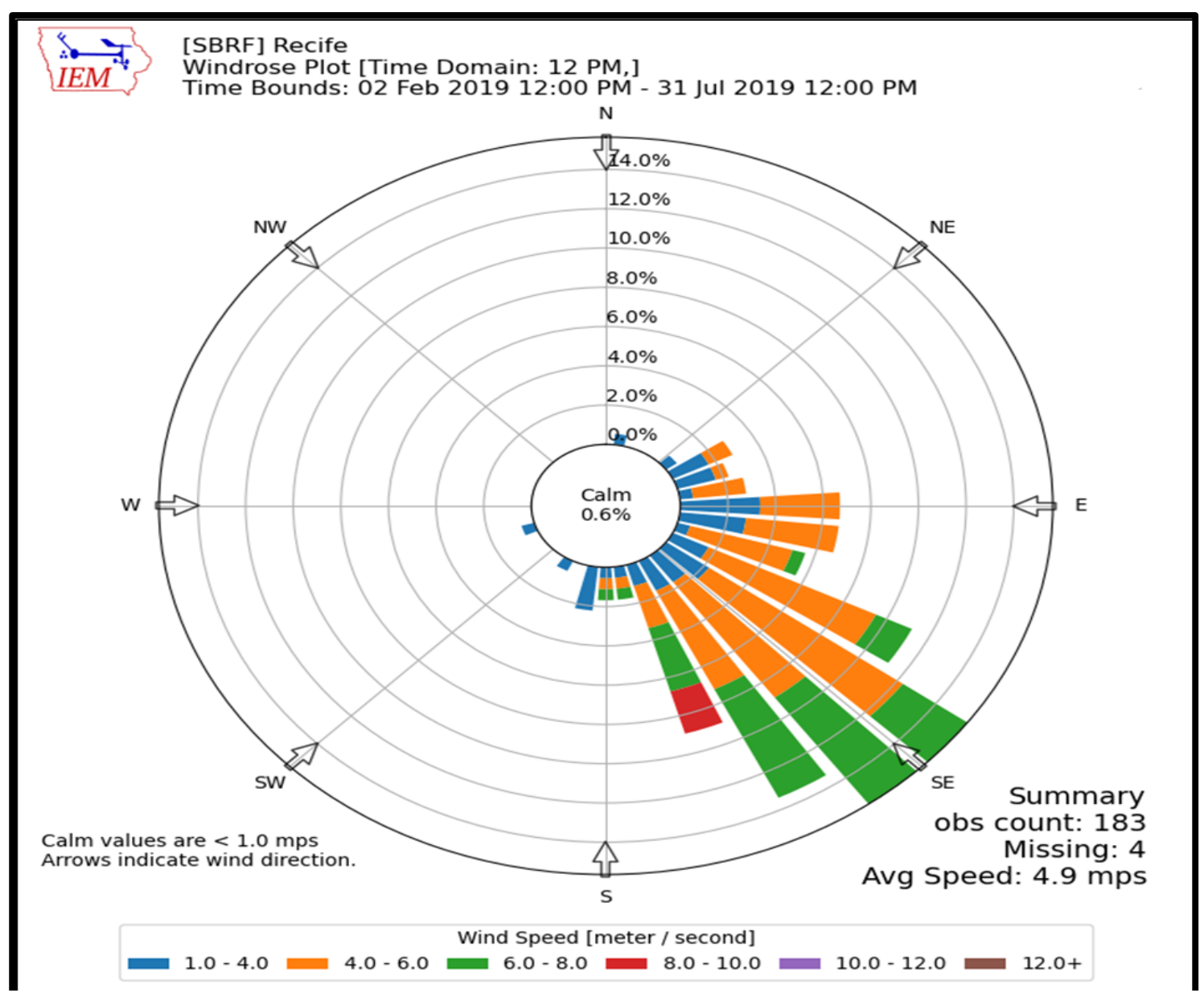

Figura 4. Rosa dos ventos do período de fevereiro a julho de 2019. Fonte: IASTATE (2019). 
Os resultados obtidos nas pesquisas de inspeção de campo foram processados copilando as informações contidas nos formulários preenchidos pelos painelistas com os traços dos percursos cobertos registrados por meio do sistema de georreferenciamento (GPS). Nos ciclos de medição, somente os pontos de marcações significativos foram relatados e plotados em um mapa, conforme recursos de visualização e edição de mapas pelo Google Eath (Google, 2019), indicando com cores diferentes os pontos em que a presença de odores reconhecíveis provenientes da fonte sob investigação (odor da ETE Curado) foi percebido (ponto preto) e aqueles onde a presença de odores reconhecíveis provenientes da fonte sob investigação não foi percebida (ponto branco) (Figura 5). A área inspecionada nos ciclos de mensuração contemplou diversos locais do território de pesquisa, conforme a região delimitada pelo tracejado na cor amarela no mapa, exceto os locais com as características topográficas limitantes. A distribuição estratégica de posicionamento dos painelistas em áreas do território investigado, a partir do entorno da ETE Curado, procedeu da seguinte forma, (1) no terminal integrado de passageiros - TIP (lat. S $8^{\circ} 3^{\prime} 53,899^{\prime \prime}$ e long. $034^{\circ} 58^{\prime} 53,047^{\prime \prime}$ ), nas áreas de estacionamento, entrada da ETE Curado, acessos de veículos, interior do TIP e sua parte externa limitada pela

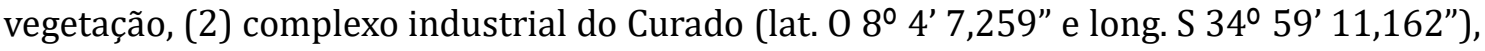
na avenida Prefeito Antônio Pereira e nas Ruas Min. Mário Andreaza e Poeta Carlos Drumond de Andrade, (3) em torno e no interior da Associação Cultural Japonesa do Recife (lat. $08^{\circ} 3^{\prime} 47,434^{\prime \prime}$ e long. S 34 59' 12"), (4) na rodovia BR 408 no trecho compreendido entre o acesso da Rua Girassol (lat. $08^{\circ} 4^{\prime}$ 14,516" e long. S 34 59' 29,303") e próximo ao acesso do Condomínio Alphaville (lat. $08^{\circ} 3^{\prime}$ 26,158" e long. S 34 59'42,461"); (5) no Curado IV (lat. $08^{\circ} 4^{\prime}$ 0,026" e long. S 340 59' 44,938") nas Ruas Girassol, Dois, Três e Sete; (6) no Condomínio Alphaville (lat. $08^{\circ} 3^{\prime} 49,039^{\prime \prime}$ e long. S 34 59' 50,266"), da Rua 01 à Rua 08.

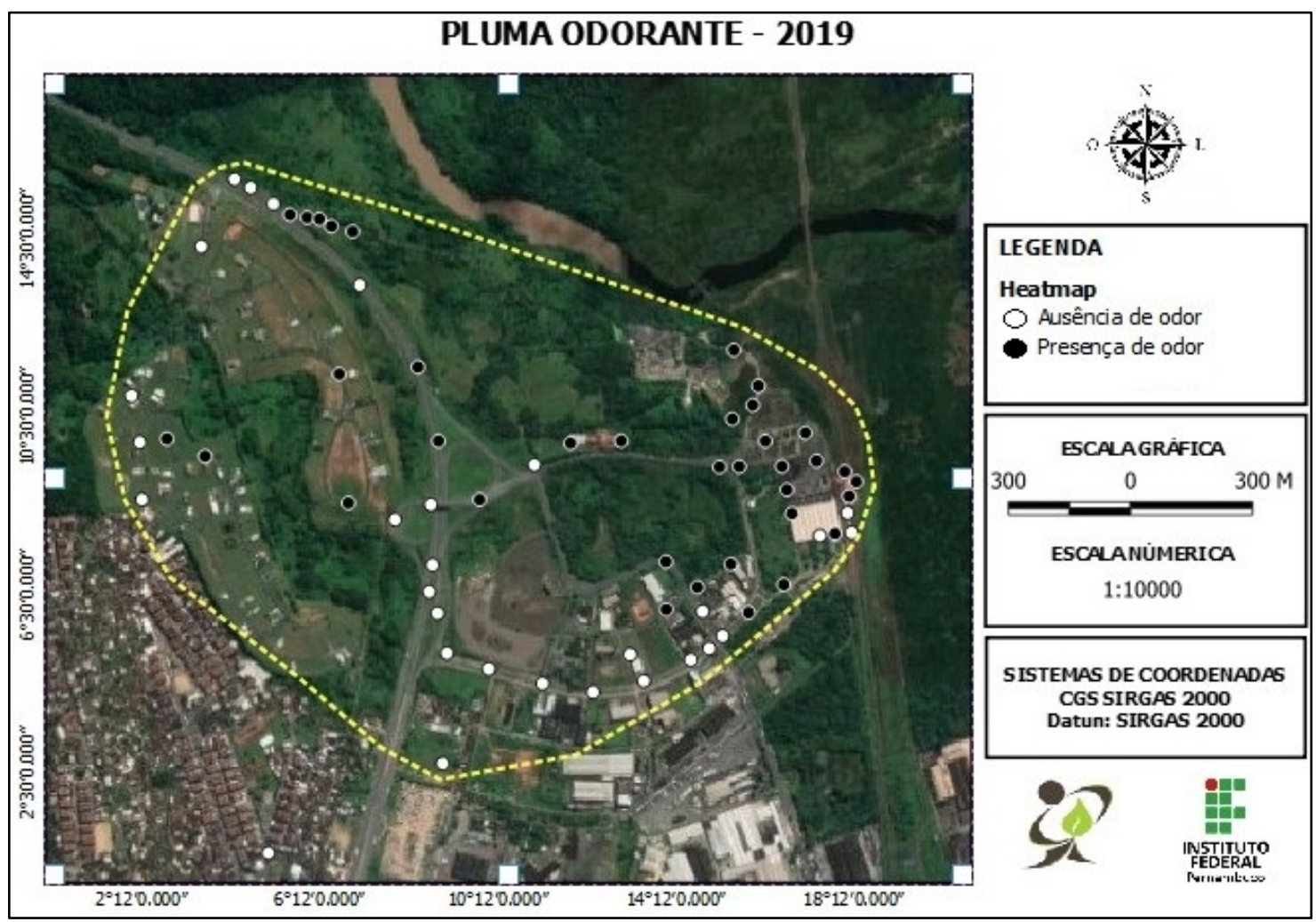

Figura 5. Área de inspeção de campo contemplada nos ciclos de mensuração. 
A área estimada do território de movimentação da pluma totalizou $9.836 \mathrm{~m}^{2}$ (Figura 6). A inspeção de campo com resultados objetivos situou-se com extensão máxima de $1331 \mathrm{~m}$ da fonte, ETE Curado e a extensão total dos pontos equidistantes pesquisados desde o TIP até o Alphaville mediu $1762 \mathrm{~m}$ de comprimento e a largura da pluma, que caracterizou-se pela deformação, apresentou um estreitamento no centro, sendo irregular em três principais pontos, o primeiro na região do TIP com 686 m, o segundo, BR 408, com $253 \mathrm{~m}$ e o terceiro na comunidade do Alphaville, com $802 \mathrm{~m}$. A largura média da pluma de $580 \mathrm{~m}$ (Figura 5). As marcações resultantes das inspeções de campo realizadas pelos painelistas totalizaram 2220 registros, deste total, com 774 inspeções com identificação de presença de odor (35\%), com uma média de identificação da presença de odor, por painelista, de 129 marcações (17\%). Quanto da relação entre o quantitativo de marcações e o quantitativo de identificação exitosa de odor, parametrizado em percentual, a inspeção em campo indicou ausência da presença de odor $(0 \%)$ no Curado IV, na rodovia BR 408 e na Comunidade Japonesa, com percentuais semelhantes (33\%), complexo industrial (41\%), TIP (42\%) e o maior percentual (53\%) no condomínio do Alphaville.

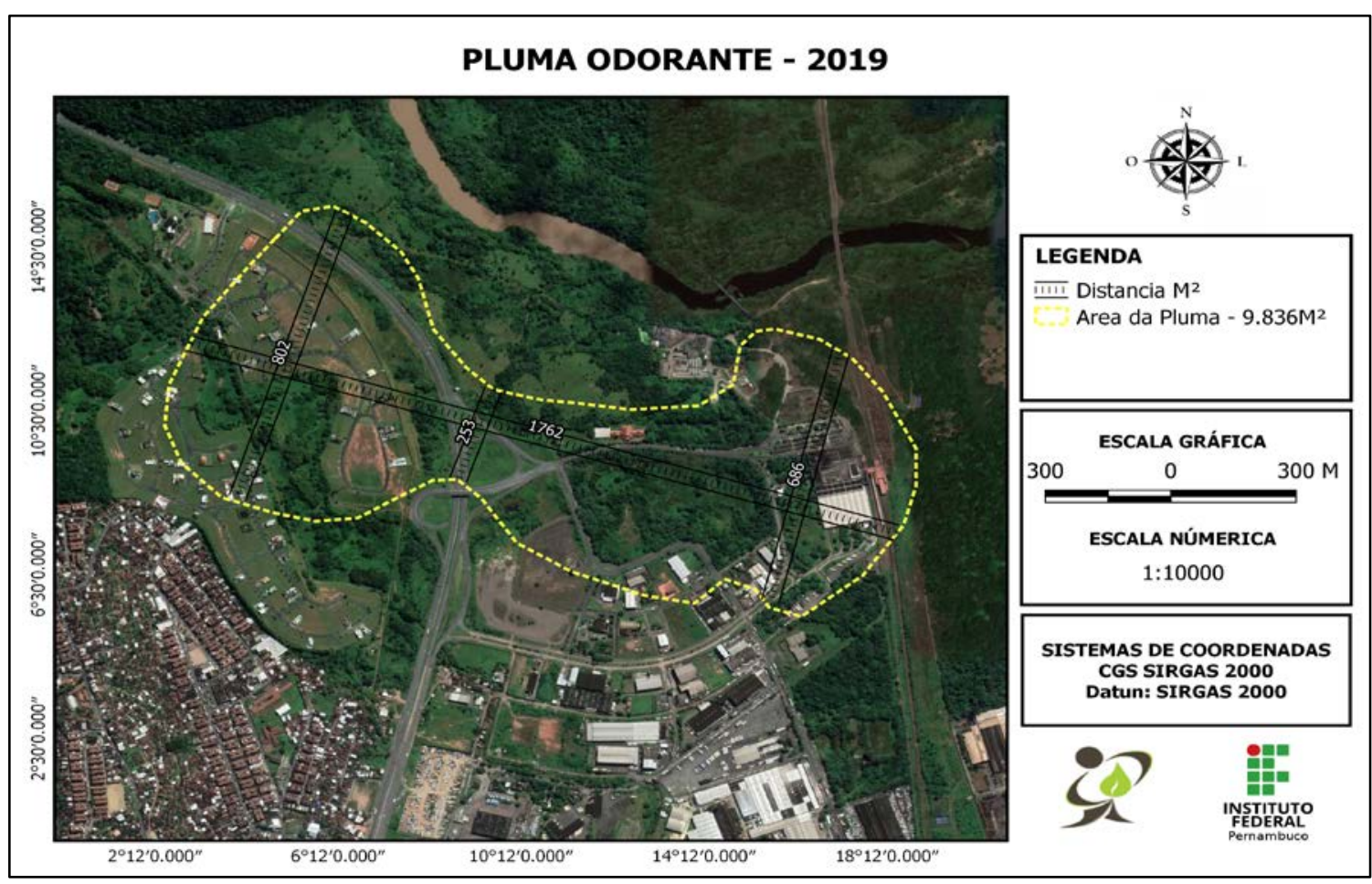

Figura 6. Medição do raio da pluma odorante

A formação, flutuação e posicionamento da pluma de odor sofreu influências das condições de tempo e da fase do dia. Observou-se que, no TIP, Complexo Industrial e Comunidade Japonesa a percepção do odor ocorreu com notada frequência nos períodos de final de tarde, noite e início de manhã. Neste lapso de tempo, houve uma menor atividade cinética dos ventos, visto que, a radiação solar é menos intensa, os ventos noturnos são menos intensos que os diurnos, a ocorrência de menor atuação do gradiente de pressão e a intensidade da turbulência termodinâmica é bem menor que a intensidade registrada durante o dia na camada limite da atmosfera (CLA). A pluma de odor oriunda da ETE Curado, neste cenário, tende à acomoda-se próximo a fonte, com a dispersão lenta no ambiente e abarcando esses locais com maior concentração odorífica, sendo a percepção 
do odor facilmente factível (Figura 7). A dispersão do efluente gasoso flui pós o aumento da velocidade dos ventos no decorrer do dia, ocorrendo mais lentamente na Comunidade Japonesa por situa-se no menor perímetro de distanciamento da ETE. Na rodovia BR 408 e residencial Alphaville, as parcelas de ventos arrastam a pluma com direção predominante de sul-sudeste (Figura 4) e força média de $4,5 \mathrm{~m} / \mathrm{s}$. Os fluxos de ventos seguem em sentido ETE Curado, na direção da cidade de São Lourenço da Mata, praticamente em paralelo ao residencial Alphaville, no entanto as massas de ar sofrem processo de perda de velocidade e desvio de direção, devido à existência de rugosidades naturais (relevo e vegetação). A resistência a velocidade dos ventos ocorre pela friç̧ão de parcelas de ar com as barreiras naturais. No primeiro momento devido ao terreno, ensejado pelo condicionante orográfico de localização da ETE, situado na parte mais baixa do território, que é caracterizado pela irregularidade do relevo e no segundo momento; de maior influência, devido ao atrito proporcionado pela vegetação de pouca homogeneidade, com ampla densidade e de presença predominante no território, que proporciona uma ação temporária de confinamento da pluma na região. A deformação dos fluxos de ventos, que consequentemente modifica a pluma, é resultado do desvio de direção ocasionado pelo impacto de massas de ar com a área vegetada por mata atlântica (Figura 8) e relevo irregular, que funciona, analogamente, como parede, lateralizando horizontalmente à esquerda a pluma de odor, sendo limitada verticalmente pela CLA (camada limite da atmosfera). 0 espalhamento da pluma flui ocupando os espaços em áreas próximas, com predominância de vegetação baixa ou área desmatada, com maior frequência notada da percepção odorífica na rodovia e no residencial Alphaville e progressivamente com o distanciamento no sentido oposto da barreira natural a percepção odorífica decai até atingir o limite de inexistência notada de frequência de odor, ou seja, quando atingi comunidade do Curado IV. A dispersão e concentração da pluma na localidade é determinada pela velocidade e direção dos ventos, influenciadas pelo período do ano e do condicionante climatológico.

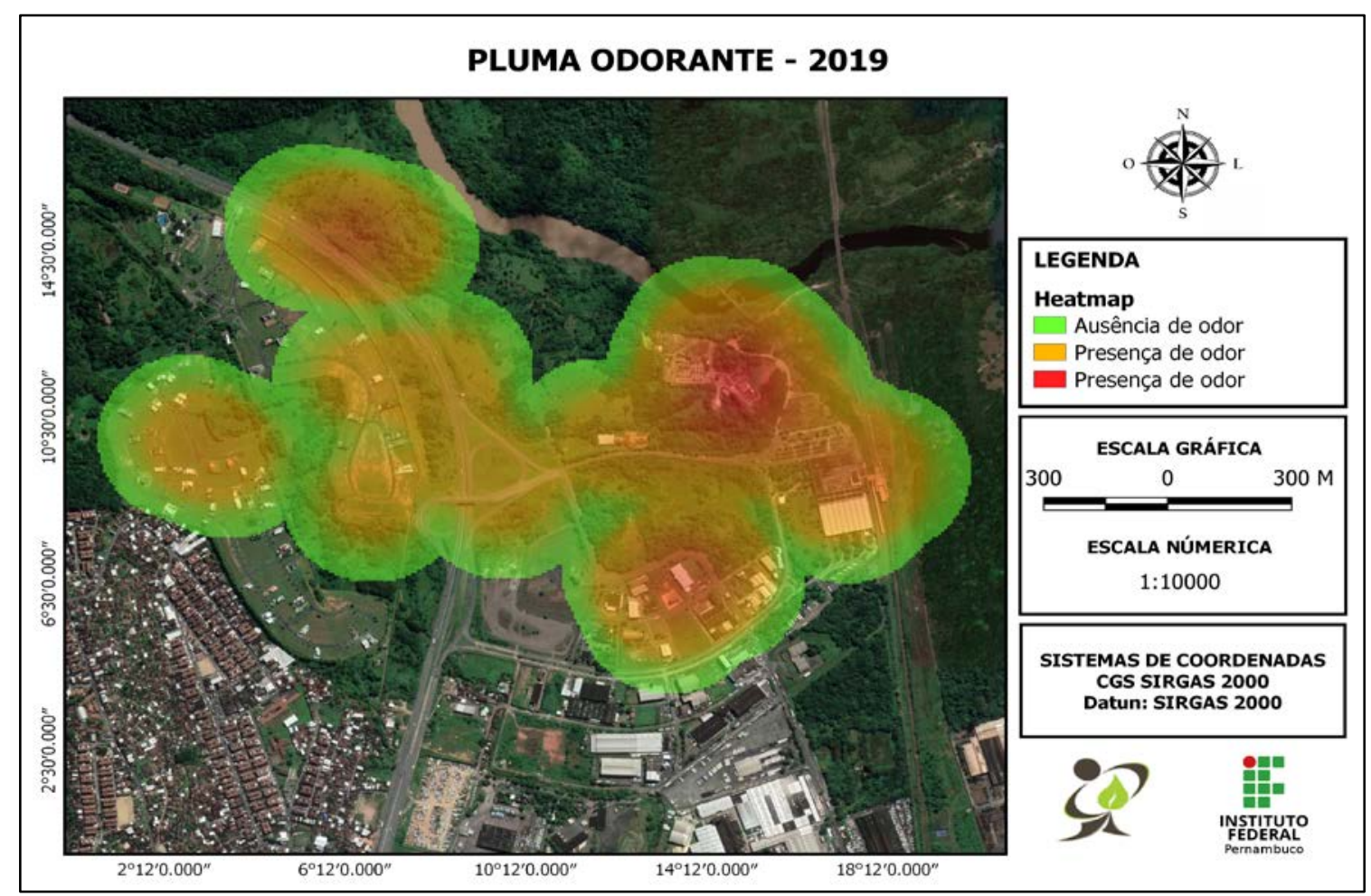

Figura 7. Pluma dinâmica odorante da ETE Curado. 


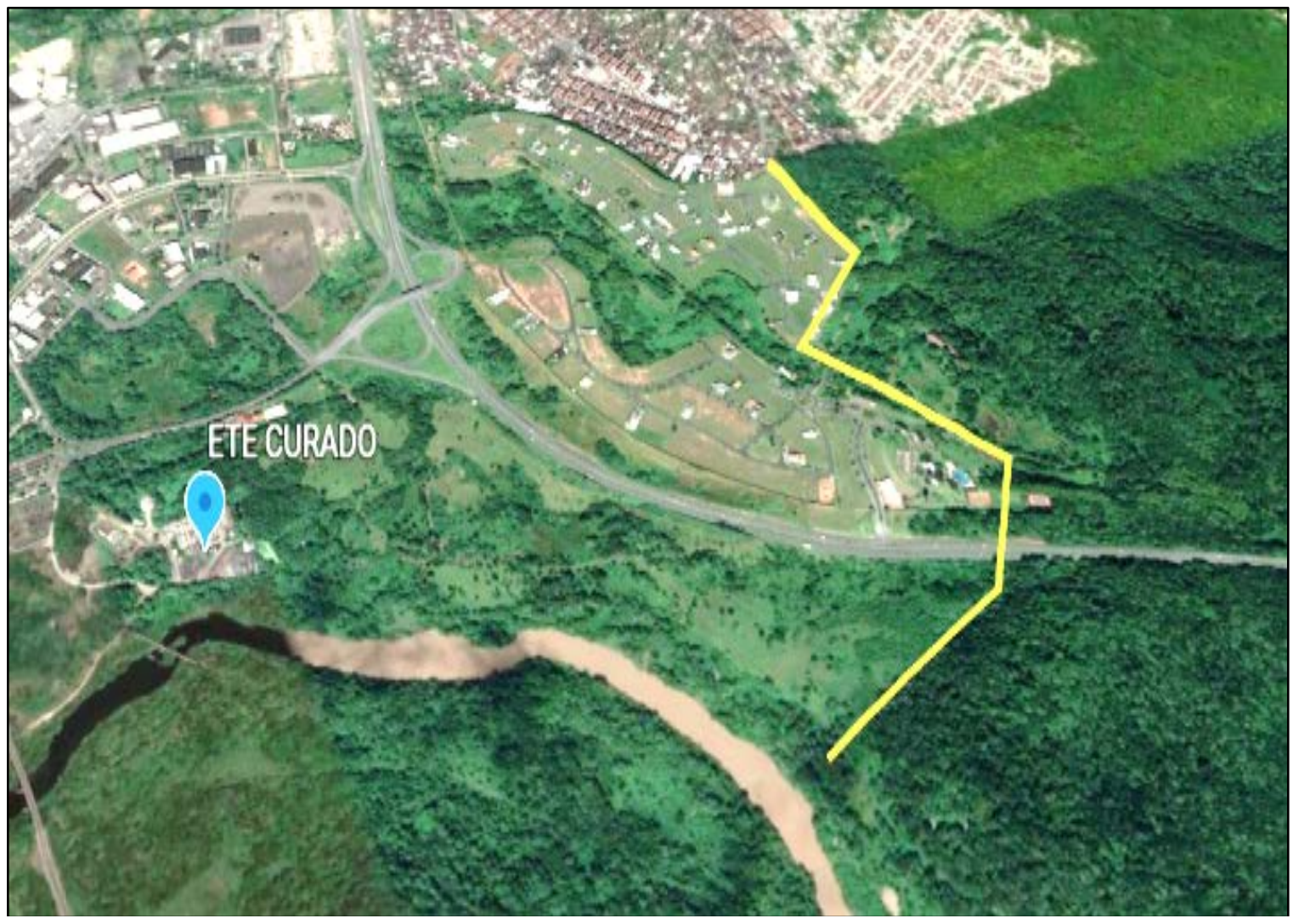

Figura 8. Barreira natural de obstaculização da pluma de odor. Fonte: Google Earth (2020)

\section{Discussão}

As medições da pluma de odor realizadas em locais estratégicos no território circundante a estação de tratamento de esgotos ETE Curado associadas à modelação direta revelou a extensão territorial de flutuação da pluma odorante, com $9.836 \mathrm{~m}^{2}$ de área mensurada e extensão máxima entre pontos equidistantes de $1762 \mathrm{~m}$, mediante o procedimento metodológico regulamentado pelo método alemão VDI 4302-2. A extensão máxima mensurada encontra equivalência com os resultados produzidos nos estudos realizados na cidade de Melbourne (Austrália). Em Melbourne, o estudo desenvolvido no lapso temporal de seis meses, focalizou no evento odorante incomodante produzido em decorrência do tratamento de resíduos sólidos orgânicos, advindos de aterros sanitários e unidades de compostagem, com odores notados a partir de $200 \mathrm{~m}$ de distância da fonte e reconhecidos a uma extensão territorial não superior a 2000 m (Bydder e Demetriou 2019). A determinação da pluma de odor, mediante a mensuração territorial de flutuação, usando o método dinâmico, apresenta resultados fiáveis na compreensão do fenômeno, perpassando ajustes plausíveis a despeito de especificidades de legislação, característica de clima, relevo e técnicas locais. 0 processo inspeção de campo foi limitada às áreas sem restrições topográficos e de vegetação de mata atlântica. 0 método adotado recomenda uma pesquisa em campo com duração de meio ano, com a possibilidade de prolongar até um ano. Neste sentido, os resultados obtidos no lapso temporal de seis meses, somado as informações coletadas sobre a direção e força dos ventos, características do relevo e vegetação local congrega elementos suficientes para compreensão do fenômeno nos períodos posteriores. 
Os fatores preponderantes de localização e formação da pluma de odor são norteados por aspectos climatológicos da região, como temperatura e regime dos ventos. A radiação solar determina a atividade cinética dos ventos, seja nas estações quentes ou durante o dia, fomentando maiores velocidades e as baixas velocidades nas estações frias ou durante o período noturno (Brand, 2014). 0 perfil histórico de velocidades dos ventos entre fevereiro e julho de 2019 concentram-se no intervalo entre 4,0 m/s e 6,0 m/s (Figura 4), a velocidade média dos ventos no ano em estudo foi de $4,8 \mathrm{~m} / \mathrm{s}$. A direção dos ventos se concentrou no segundo quadrante da rosa dos ventos (Figura 4) com predominância de direção sul-sudeste. A força dos ventos no ano e no período estudado se manteve invariável, conforme a escala Beaufort, ou seja, em ambos os casos, de número 3. Que representa uma força cinética fraca na movimentação de parcelas de ventos que, consequentemente, movimentam lentamente a pluma odorante na região, com ganho de velocidade e dispersão durante o dia e o efeito inverso durante a noite, confinando a pluma de odor próximo a fonte. Os fluxos de ventos sofrem a ação limitante devido as características de vegetação e relevo. Resultado da perda de força dos ventos determinada por rugosidades naturais e o desvio de direção ocasionado pelo impacto de massas de ar com a área vegetada, promovendo o espalhamento da pluma de odor na microrregião, destacadamente na Comunidade do Alphaville.

A adoção do método da pluma dinâmica (VDI 4302-2) produziu resultados críveis na compreensão do fenômeno, mediante a inspeção em campo por painel humano qualificado, método de aplicação direta, simples e menos onerosa. A percepção do odor reconhecível de uma fonte sabida confere ao painelista registrar as informações a despeito da extensão territorial de flutuação da pluma, percebendo in loco e verossímil, a reprodução aproximada do nível de incomodidade que acomete a comunidade local. 0 estudo não sofreu interferências por odores de fontes difusas, devido a especificidade do odor de uma estação de tratamento de esgotos e pela invariabilidade de direção dos fluxos de ventos. Os dados obtidos também servem para subsidiar a melhor escolha de instalação de um empreendimento com real potencial de emitir o efluente odorante incomodante na microrregião, não excluindo na avaliação a congregação dos os aspectos relacionados ao clima, relevo, orografia e regime dos ventos.

Como medida de enfrentamento e mitigação dos impactos e fomento ao melhor conforto dos moradores e circulantes na região, sugere-se, em princípio, a instituição de estudo ambiental para o plantio de árvores situadas de forma estratégica na região, com a função de barreira verde, assentado em informações referentes ao regime de ventos da microrregião e optando, preferencialmente, na escolha de espécies vegetais de ocorrência local. No segundo momento, aponta-se como alternativa viável o monitoramento compartilhado, envolvendo a comunidade e o empreendimento para monitoramento de evento de odor anormal, mediante relato de queixa via Internet. Neste sentido, pauta-se também a importância da constituição de um comitê de gestão permanente formado por representantes locais e da empresa gestora da ETE para tratar do tema e das proposituras de resoluções, com intuito de pactuar medidas de minimização do impacto ambiental do odor na região e promover a governança local. 0 uso de ferramentas de apoio a gestão estratégica da temática faz-se pertinente para garantir a implantação de medidas e do controle dos resultados.

\section{Conclusões}

Os resultados da inspeção de campo a despeito dos limites de percepção de odores emitidos e identificados a partir de uma fonte sabida, ETE Curado, no período de seis meses do ano de 2019, em condições climatológicas características da microrregião, apontaram para um julgamento de que, os odores emitidos e espalhados na região proporcionam incômodos, percebidos em intervalos variáveis de tempo no transcurso do 
dia, nas localidades estudadas, exceto na comunidade do Curado IV. A percepção do efluente odorante, por painel humano qualificado, foi relatado em $84 \%$ do território estudado. As medidas de modelação da pluma apresentaram as dimensões de $9.836 \mathrm{~m}^{2}$ de área, largura média de 580 m e extensão máxima entre pontos equidistantes de $1762 \mathrm{~m}$. Os ventos predominantes no lapso temporal de estudo foram sul-sudeste, com força média de $4,9 \mathrm{~m} / \mathrm{s}$ e com grau na escala Beaufort de número 3, considerada uma brisa leve, restringiram a ação dissipadora do efluente. 0 posicionamento da pluma sofre alterações dependendo do horário do dia, devido à modificação/variação na microrregião do gradiente de pressão. No período noturno se concentra numa área próxima à fonte e, durante o dia, é movimentada por parcelas de ar para outra área afastada da fonte. Durante o dia, a baixa atividade cinética dos ventos movimenta lentamente o efluente odorante, o confinando temporariamente numa área de acomodação, em razão de características orográficas do local e da vegetação circundante.

Nesse contexto, estudo desenvolvido produziu informações circunstanciadas sobre as dimensões territoriais de flutuação da pluma odorante para nortear a compreensão do fenômeno e subsidiar novos estudos, a elaboração de projetos ambientais e a gestão ambiental do empreendimento, sob um viés do aperfeiçoamento do planejamento das operações e, noutro viés de fomento a relação dialógica com a comunidade circundante para uma gestão compartilhada no enfrentamento do desafio exposto.

\section{Conflito de interesses}

Os autores declaram não haver conflito de interesses.

\section{Referências}

ABNT - Associação Brasileira de Normas Técnicas. ABNT NBR ISO 8589:2015. Análise sensorial - Guia geral para o projeto de ambientes de teste. Rio de Janeiro: ABNT, 2015.

ABRELPE - Associação Brasileira das Empresas de Limpeza Pública e Resíduos Especiais. Panorama Geral de Resíduos Sólidos - 2018 e 2019. Disponível em: <https://abrelpe.org.br/panorama/>. Acesso em: 10 mar. 2020.

ASTM International. ASTM E679-04:2011. Standard practice for determination of odor and taste thresholds by a forced-choice ascending concentration series method of limits. West Conshohocken: ASTM International, 2011. Disponível em: <https://www.astm.org/DATABASE.CART/HISTORICAL/E679-04R11.htm>. Acesso em: 24 ago. 2019.

ASTM International. ASTM E544-18:2010. Standard practice for referencing suprathreshold odor intensity. West Conshohocken: ASTM International, 2010. Disponível em: <https://www.astm.org/Standards/E544.htm>. Acesso em: 28 ago. 2019.

Belli Filho, P.; Silva, G. P.; Santo, C. L.; Lisboa, H. M.; Carmo Junior, G. N. Avaliação de impactos de odores em bacias hidrográficas com produções de suínos. Engenharia Sanitária e Ambiental, v. 12, n. 3, p. 252-258, 2007. https://doi.org/10.1590/S141341522007000300004

Brand, S. I. Caracterização da direção e velocidade dos ventos em Santa Rosa-RS. Cerro Largo: Universidade federal da Fronteira Sul, 2014. (Monografia de graduação). 
Brattoli, M.; Mazzone, A.; Giua, R.; Assennato, G.; Gennaro, G. Automated collection of realtime alerts of citizens as a useful tool to continuously monitor malodorous emissions. International Journal of Environmental Research and Public Health, v. 13, n. 3, 263, 2016. https://doi.org/10.3390/ijerph13030263

Bydder, C.; Demetriou, J. Establishing the extent of odour plumes and buffers for waste handling facilities. Waste Management, v. 95, p. 356-364, 2019. https://doi.org/10.1016/ j.wasman.2019.06.028

Capanema, M.; Belli Filho, P.; Lisboa, H. M.; Schirmer, W. Principais metodologias de avaliação físico-química e olfatométrica de compostos orgânicos voláteis (COV) e odorantes: uma breve revisão. Anais do XXVII Simpósio Luso Brasileiro de Engenharia Sanitária e Ambiental, Florianópolis, 2016.

Carmo Junior, G. N. R. Otimização e avaliação de metodologias olfatométricas voltadas ao saneamento ambiental. Florianópolis: Universidade Federal de Santa Catarina, 2015. (Tese de doutorado).

CEN - European Committe for Standardization. EN 16841-1:2016. Ambient air Determination of odour in ambient air by using field inspection - Part 1: Grid method. CEN, 2016. Disponível em: <https://standards.cen.eu/dyn/www/ $\mathrm{f}$ ?p=204:110:0::::FSP_PROJECT:27463\&cs=1071E1CBDA27EAC763C3309C6045627DE >. Acesso em: 25 out. 2018.

CEN - European Committe for Standardization. EN 16841-2:2016. Ambient air Determination of odour in ambient air by using field inspection - Part 2: Plume method. CEN, 2016. Disponível em: <https://standards.cen.eu/dyn/www/ $\mathrm{f}$ ?p=204:110:0::::FSP_PROJECT:36894\&cs=1BDABC1110D6AE27EC905C5B1E3BB1750>. Acesso em: 25 out. 2018.

Fachbereich Umweltmesstechnik. VDI 4302-1. Geruchsprüfung von Innenraumluft und Emissionen aus Innenraummaterialien - Grundlagen. Düsseldorf: VDI/DINKommission Reinhaltung der Luft - Normenausschuss., 2015.

Google. Google Earth. 2019. Disponível em: <https://www.google.com.br/intl/ptBR/earth/>. Acesso em: 17 out. 2020.

IASTATE - Iowa State University. Mesonet wind rose. 2019. Disponível em: $<$ https://mesonet.agron.iastate.edu/sites/windrose.phtml?network=BR_ASOS\&station=S BRF>. Acesso em: 7 out. 2019.

INMET - Instituto Nacional de Meteorologia. 2020. Disponível em: <http://www.inmet.gov.br/portal/>. Acesso em: 4 maio 2020.

ISO - International Standard International Standard. ISO 16000-28:2012. Indoor air Part 28: Determination of odour emissions from building products using test chambers. Genebra: ISO, 2012.

McGinley, M. A.; McGinley, C. M.; Jeff, M. Olfactomatics: Applied mathematics for odor testing. Anais do WEF ODOR/VOC 2000 Specialty Conference, Autin, 2000.

Mendes, L. R. T. Emissão e controlo de odores em aterros sanitários. Aveiro: Universidade de Aveiro, 2012. (Dissertação de mestrado).

Schirmer, W.; Lacey, M.; Lisboa, H.; Vieira, M.; Rosso, L.; Campos, G.; Rodrigues, M. Análises olfatométricas para determinação das características do odor no Manguezal do Itacorubi, Município de Florianópolis, Santa Catarina. Revista de Ciências Ambientais, v. 2, n. 1, p. 57-72, 2008. 
Silva, M. T. S. Emissões atmosféricas odorantes de uma estação de tratamento de efluentes: limites geográficos da pluma. Recife: Instituto Federal de Educação, Ciência e Tecnologia de Pernambuco, 2020. (Dissertação de mestrado).

Sironi, S.; Capelli, L.; Céntola, P.; Del Rosso, R.; Il Grande, M. Odour emission factors for assessment and prediction of Italian MSW landfills odour impact. Atmospheric Environment, v. 39, n. 29, p.5387-5394, 2005. https://doi.org/10.1016/j.atmosenv. 2005.05.023

Vieira, M. M. Abordagem de procedimentos legais para o controle de incômodos olfativos. Florianópolis. Universidade Federal de Santa Catarina, 2013. (Dissertação de mestrado).

Yang, Y. The influence of tannin and tannin with salivary protein on the volatility and the perceived intensity of ethyl hexanoate in a wine-like solution. Lincoln: Lincoln University, 2017. (Dissertation). 